\title{
Tecendo uma cidade modelar: relações entre escola, currículo e projeto da cidade de Curitiba*
}

\author{
Weaving a model city: relations between curriculum, school education and \\ design of Curitiba
}
Tejendo una ciudad ejemplar: relaciones entre currículo, educación escolar y proyecto de la ciudad de Curitiba

VALÉRIA MiLENA ROHRICH FERREIRA** \begin{abstract}
$\diamond$
\section{RESUMO}

Em 1990 e início do século XXI Curitiba apresentava um projeto explícito de cidade que se fortalecia por meio de diferentes campos, inclusive do educacional. Este artigo analisa tal fortalecimento e a participação do campo educacional neste processo. Evidenciou-se a existência de grupos estabelecidos que aumentavam sua coesão por meio do êxito do projeto da cidade, assegurado por discursos performativos de grande poder simbólico (Bourdieu) enquanto grupos outsiders (Elias), tanto pelo conteúdo da crítica quanto pelo modo de veiculação, não conseguiam fazer valer os seus pontos de vista. No campo educacional a secretaria municipal de educação produziu e entregou às escolas uma série de materiais curriculares que reforçavam o projeto estabelecido da cidade, conformando as crianças à imagem de uma cidade modelar em que as desigualdades sociais e raciais eram invisibilizadas.
\end{abstract}

Palavras-chave: Projeto de cidade. Educação escolar. Currículo. Curitiba. Elias.

\begin{abstract}
In the last decade of the twentieth century and at the beginning of XXI Curitiba had an explicit design of the city that grew stronger through different fields, including the education, leading to examine both, the project itself and a place of school education in it. The collected data demonstrated the existence of established groups that increased their cohesion through the project's success ensured by the development of performing opinions of great symbolic power (Bourdieu). What about the outsiders groups (Elias), they could not enforce their views because of the contents and the manner they used to bring their critics. The analysis of official curriculum materials form the municipal schools showed in general, that its contents reinforced the established project of the city, fostering the political apathy of the citizens and making children accept the image of a model city where social and racial inequalities were relegated to the background or even made invisible.
\end{abstract}

Keywords: City project. School education. Curriculum. Curitiba. Elias.

\section{RESUMEN}

En 1990 y comienzo del siglo XXI, Curitiba presentaba un proyecto explícito de ciudad que se hacía más fuerte por medio de distintos campos, incluso el educacional. Este artículo analiza tal fortalecimiento y la participación del campo educacional en la marcha de este proyecto. Se hizo perceptible la existencia de grupos establecidos que aumentaban su cohesión por medio del éxito del proyecto de la ciudad, garantizado por discursos performativos de gran poder simbólico (Bourdieu), mientras grupos outsiders (Elias), tanto por el contenido de la crítica como por el modo de difusión, no lograban hacer valer sus puntos de vista. En el campo educacional, la Secretaría Municipal de Educación produjo y entregó a las escuelas una serie de materiales curriculares que reforzaban el proyecto establecido de la ciudad, conformando los niños a la imagen de una ciudad ejemplar donde las desigualdades sociales y raciales eran hechas invisibles.

Palabras clave: Proyecto de ciudad. Educación escolar. Currículo. Curitiba. Elias.

\footnotetext{
*Este artigo, com algumas modificações, foi apresentado no X Congresso Luso-Afro-Brasileiro de Ciências Sociais: Sociedades desiguais e paradigmas em confronto. Braga/Portugal/2009. A pesquisa aqui em parte relatada foi realizada em estudos de doutoramento com apoio da CAPES.

**Professora do Setor de Educação da Universidade Federal do Paraná. Mestre e Doutora pela PUC/SP, Programa Educação: História, Política e Sociedade (EHPS). Pós-doutorado na Universidade Lumière Lyon 2 (grupo de pesquisa: Modos, Espaços e Processos de Socialização). E-mail: <valeriarohrich@ gmail.com>.
} 


\section{INTRODUÇÃO}

Curitiba apresentava, na década de 1990 e nos primeiros anos do século XXI, um projeto de cidade explícito, fruto de uma construção não só desse período, mas, também, de décadas anteriores. Diversos grupos, advindos de diferentes instituições e campos, produziram ideias, símbolos, práticas e equipamentos sociais com o intuito de torná-lo cada vez mais consistente. Nessa rede produtora do projeto, o campo educacional, por meio de uma série de materiais curriculares produzidos no período, - alguns entregues às escolas e outros diretamente às crianças-, ajudou em muito na construção e propagação do projeto. A proposta deste artigo é, portanto, discutir como isso se deu.

Para se aproximar do que era chamado "projeto da cidade", a pesquisa partiu de algumas indagações. Haveria mesmo um projeto de cidade visível a ponto de ser capturado para análise? E, se sim, que atores, fontes e instituições o explicariam? Quem participaria dessa construção e que formas de socialização seria proposta?

Supunha-se, de início, que as palavras dos governantes e noticiários em jornais e revistas divulgados pela mídia trariam pistas sobre isso. Porém, uma primeira coleta de dados $^{1}$ evidenciou tanto um discurso já bem conhecido (sobre a cidade "ecológica", de "planejamento exemplar" etc.) quanto homogêneo, ainda que as fontes fossem diversas. Procurando obter dados mais abrangentes, realizou-se nova coleta na produção acadêmica de diferentes campos (a partir do site da Capes) e também a partir de outros materiais de circulação na cidade $^{2}$, constituindo-se, assim, um corpus bastante significativo de informações sobre Curitiba.

Por outro lado, buscou-se também uma série de materiais pedagógicos e curriculares que circulavam nas escolas, nessa mesma época.

Esses materiais, é preciso que se diga, foram "lidos" muito menos com a intenção de retirar deles uma compreensão sobre o que se falava da cidade e, muito mais, procurando conhecer o caldo de cultura curitibana da época, expresso ali e ensinado desde cedo às crianças

\footnotetext{
${ }^{1}$ Foram analisadas pastas existentes na seção Paranaense da Biblioteca Pública do Paraná, com recortes de diversos jornais e revistas de circulação no estado do Paraná (Correio, Voz do Paraná, Jornal do Estado, Correio de Notícias, O Estado do Paraná, Folha de Londrina, A Folha da Imprensa, Diário Popular, Gazeta do Povo, Indústria e Comércio, Isto é, Exame, Manchete, Veja), com notícias dos prefeitos: Lerner, nas três gestões (1971-75/1979-82/1989-92); Greca (1993-96); e Taniguchi (1997-2000/2001-2004).

2 Ver a listagem nas referências bibliográficas, em documentos analisados.

3 Por exemplo, Sanchez (2001) observou a existência de discursos dominantes e atores sociais passivos ou insatisfeitos; Moura e Kornin (2001), partindo de Milton Santos, definiram os discursos dos atores hegemônicos como instauradores de um "pensamento único"; Acselrad (2001) referiu-se a atores legítimos e deslegitimados; Almeida (2006) diz ter trabalhado com "fontes oficiais" e fontes "alternativas".
}

da rede. Procedeu-se, nesse sentido, um pouco à maneira de Elias (1994b), autor que ao analisar antigos "manuais de conduta à mesa" considerou-os como componentes da própria história de uma sociedade, ou do caldo de cultura de uma determinada época. Segundo ele, os leitores de tais manuais acabavam sendo um pouco formados por esse tipo de literatura que funcionava como uma espécie de dispositivo formador de habitus, valores e condutas.

As vozes que falavam da cidade e das práticas curitibanas, e que destacavam pessoas, mobiliários urbanos, planos e metas, vinham de diferentes campos, mas, enquanto muitos enalteciam o projeto, outros se definiam como "vozes" dissonantes, silenciadas, "invisibilizadas"3. $\mathrm{O}$ embate entre a produção de imagens, discursos e práticas por parte de alguns grupos e a sua discordância por parte de outros evidenciou uma luta de representações (BOURDIEU, 2000) pela melhor definição de Curitiba e de suas práticas. Uma luta para fazer existir ou inexistir o que existia. Esse tipo de embate revelou uma configuração social do tipo estabelecidos-outsiders (ELIAS, 1994a, 1994b, 2000) em que o acúmulo de poder por parte de determinados grupos impedia que outros pudessem também se colocar na cena urbana e ajudar na construção do projeto da cidade. O campo educacional, por meio dos materiais produzidos, fez ressoar também os discursos estabelecidos de cidade. Na sequência, o artigo se desenvolve procurando ressaltar como esse processo acontecia.

\section{IDENTIDADE DA CIDADE: IMAGENS EM DISPUTA}

Quando comparada a outras cidades brasileiras, Curitiba sempre foi enaltecidada pela grande maioria das pessoas, e, muitas vezes, não se admite nenhuma crítica que lhe possa ser feita. Concorrem a favor dessa leitura, de fato, muitos dados importantes sobre a cidade. Esta chegou ao século XXI sendo a maior cidade do Paraná em número de habitantes - com mais de 1 milhão e meio de pessoas (BOLETIM..., 2007) - e a sétima do Brasil. Teve, no último século, movimentos migratórios constantes e contava, no início dos anos 2000, com uma região metropolitana de quase 3 milhões de pessoas. A renda média dos responsáveis pelos domicílios particulares permanentes, no período, era $46 \%$ maior do que a registrada no restante do país, sendo que, em termos de distribuição de renda por classes (classificação utilizada na época), $15,22 \%$ da população pertencia à classe $\mathrm{A}$ (recebendo mais de 15 salários mínimos ) e 29,02\%, à classe B (recebendo entre 5 e 15 salários). Somadas, essas duas classes correspondiam a $44,24 \%$ do total da população, e $5,94 \%$ pertenciam à classe $\mathrm{E}$, que recebia até um salário mínimo (IBGE apud BOLETIM..., 2007). Estava em 
sexto lugar entre as capitais com maior participação no PIB nacional e em quinto lugar no ranking das capitais brasileiras que mais geravam empregos. De 1995 a 2005, o número de turistas, em Curitiba, cresceu 99\%. Estes, atraídos, muitas vezes, justamente pelo projeto de cidade "verde" (a cidade contava com 51\% de cobertura vegetal por habitante, em metro quadrado). Tinha um Índice de Desenvolvimento Humano (IDH) de $0,856 \%$ e uma taxa de alfabetização de $96,86 \%$.

Embora tais dados fossem bastante positivos, dando à cidade, na época, visibilidade dentro e até fora do país, sempre se acrescentaram a tais divulgações, slogans e títulos repetidos insistentemente. Muitos deles, distanciando-se cada vez mais da realidade de grande parte dos curitibanos, ou produzindo sentido apenas para alguns moradores da cidade. Assim, muitos grupos fortalecedores do projeto passaram a desenvolver imagens e ações cada vez mais relacionadas à ideia de que a cidade era "modelo", "correta", "limpa", "verde". Tais imagens e ações, entrando em confronto com as produzidas por outros grupos, causavam tensões que pareciam estar relacionadas às práticas de socialização oferecidas pela cidade e também ao modo com que cada cidadão passava a compreender a si e aos outros moradores da cidade.

Para analisar tais tensões, seria possível partir do contexto de urbanização intenso vivido pelas cidades, de modo geral, no último século. Se, por um lado, diferentes grupos com poder vieram atuando de forma a intensificar e espraiar o sistema capitalista para a quase totalidade do mundo; por outro, tal sistema foi e ainda é absorvido, interpretado e causa práticas diferentes nos diversos lugares por onde se desenvolve. Assim, embora existam características de exclusão e perversidade iguais nos diversos lugares do mundo, o que torna as cidades, inclusive, tão parecidas, também há diferentes modos de sobrevivência e formas bastante distintas de jogar o jogo do capital.

Dessa forma, uma explicação possível para a Curitiba da década de 1990 e início do século XXI poderia se sustentar no argumento de que atores sociais do período, assim como os de tantas outras cidades, estariam procurando assegurar a permanência da cidade no novo mapa econômico do mundo. Cidades assim produzidas se transformariam, nas palavras de Sánchez (2001), em verdadeiras city marketing, em "tecnópolis" a serviço do capital. Estas, por prometerem alta qualidade de vida, renovação cultural e artística, passariam a ser uma marca, um produto transparente, simplificado e genérico, ou seja, verdadeiras "cidades-vitrine". E, para isso, Curitiba cumpriu a pauta corretamente: seguiu padrões internacionais de atração de investimentos, criou espaços eficientes do ponto de vista econômico - arquitetura exuberante de equipamentos urbanos, por exemplo, ou atração de multinacionais -, investiu no turismo e divulgou uma quantidade enorme de slogans.

Mas, se não deixa de ser verdade que Curitiba apresentava-se como um produto competitivo, sublinhar tal explicação - no caso desta pesquisa - poderia produzir o efeito de se "carregar nas tintas" da estrutura ou esbarrar em um enfoque economicista. Excluindo-se, assim, de antemão, uma análise detida nos aspectos da cultura curitibana. Sobre esse risco, vale lembrar que "todo monopólio 'econômico', seja qual for a sua natureza, direta ou indiretamente, liga-se a outro, sem o qual não consegue existir" (ELIAS, 1994a, p. 42). E, parecia que, justamente, os aspectos da cultura é que forneceriam pistas para a compreensão do porquê da força do projeto da cidade.

Assim, o cuidado deveria ser também o de evitar uma apreensão da cidade a partir de uma visão "supraindividual" (ELIAS, 1994a), ou seja, a de que haveria um "espírito curitibano" orientando os rumos do projeto da cidade. Ainda outra possibilidade de explicação poderia partir das transformações positivas ocorridas em Curitiba, nas últimas décadas do século XX. Nesta, invariavelmente, apareceria a figura do prefeito Jaime Lerner: pai dos curitibanos, empresário-arquiteto e urbanista de sucesso, um verdadeiro mito vivo. Sobre ele, bastaria ainda acrescentar que foi prefeito por três vezes nos últimos 30 anos do século XX (1971-75/197982/1989-92), governador por duas vezes consecutivas (1995-98 e 1999-2002) e que lançou os dois próximos prefeitos eleitos na década de 1990. Mas, com a sensação de que, se na explicação anterior poderia ser privilegiada uma explicação do tipo "sociedade sem indivíduos", nesta, pelo contrário, seria produzida a ideia de um "indivíduo acima da sociedade", responsável pelo sucesso curitibano. Esse último tipo de explicação aceitaria analisar indivíduos em separado, "como postes sólidos entre os quais, posteriormente, se pendura o fio dos relacionamentos" (ELIAS, 1994a, p. 25).

Não querendo correr o risco de separar indivíduo e sociedade, uma possibilidade foi procurar compreendêlos como "redes sociais", no sentido que Elias propôs. Para esse autor, todos os seres humanos são dependentes uns dos outros e formam, por assim dizer, redes de interdependência que produzem o nexo a que se chamou de configuração, ou seja, uma estrutura de pessoas mutuamente orientadas e dependentes. As redes são compostas por práticas que se consagram tão fortemente que se confundem com os próprios sujeitos, tornando-se inconscientes, uma segunda natureza no homem, ou seja, costumes, condutas transformadas em hábitos.

Para se compreender, portanto, a configuração de Curitiba daquele período, as tensões entre grupos e o modo como se ensinava sobre a cidade às crianças, sabia-se 
que seria preciso investigar atores, grupos e instituições nas suas relações, nas suas redes de interdependência.

\section{REDES ESTABELECIDAS: ESTRATÉGIAS DE COESÃO ENTRE GRUPOS E CONTRIBUIÇÕES DO CURRÍCULO ESCOLAR NA TESSITURA DO PROJETO DA CIDADE}

A escola curitibana da década de 1990 e início do século XXI fazia parte de uma configuração social da cidade, mais ampla que esse período, constituída nos últimos 60 ou 70 anos. Foi nessa época que a cidade passou a constituir uma nova configuração, relacionada, entre tantos outros aspectos, a novos equipamentos públicos construídos; à necessidade de planejamento constante pelo seu crescimento; à industrialização paranaense; e, mesmo antes disso, à construção de uma identidade própria para o $\mathrm{Pa}$ raná. E, por consequência, para sua capital, Curitiba, nas primeiras décadas do século XX - por meio de um movimento artístico, literário e político denominado Paranismo. Desse modo, Curitiba, na década de 1990 e nos primeiros anos do século XXI, ao apresentar um projeto explícito de cidade, oferecia ao pesquisador pistas, tanto sobre essas raízes mais largas no tempo quanto sobre a cultura curitibana.

Como foi ressaltado por Elias, uma análise detalhada de diversos aspectos produtores dessa nova configuração social evidenciou a formação de redes de interdependência entre grupos e indivíduos que mantinham relações de poder do tipo estabelecidos-outsiders. Sendo assim, quando se pensou Curitiba, quando ações na cidade ocorreram, alguns grupos tiveram mais força, voz e autoridade, não só para explicar a cidade, mas, também, e principalmente, para direcionar a formação dos pequenos curitibanos. Como isso ocorreu? Como reuniram força para tamanha empreitada? Por que os diferenciais de poder foram tão grandes a favor desses grupos?

Uma explicação possível para tais indagações pode ser buscada na compreensão de como funciona uma configuração social do tipo estabelecidos-outsiders. Elias, ao estudar diversas configurações, percebeu nelas a existência de dois ou mais grupos que se relacionavam de sorte a que um deles acionasse determinadas vantagens (não necessariamente de classe ou de raça) utilizadas para estigmatizar os outros. Dessa forma, em suas pesquisas, verificou tensões entre negros e brancos, servos e senhores feudais, mas também entre judeus e não judeus ou mesmo entre nações superiores e nações em desenvolvimento. Em um estudo etnográfico realizado com Scotson (2000), em uma comunidade da periferia urbana da Inglaterra, Elias e seu colega perceberam ainda outras vantagens importantes utilizadas nesse processo de estigmatização. Revelaram, por exemplo, a existência de um grupo estabelecido desde longa data no local e de um grupo mais novo de residentes, e os moradores eram tratados pelos estabelecidos como outsiders. O grupo estabelecido cerrava fileiras contra eles e os estigmatizava, de maneira geral, como pessoas de menor valor humano. "Considerava-se que lhes faltava a virtude humana superior - o carisma grupal distintivo - que o grupo dominante atribuía a si mesmo" (ELIAS e SCOTSON, 2000, p. 19). Sobre as pessoas residentes nessas duas regiões estudadas, os pesquisadores descobriram que tinham o mesmo poder aquisitivo, praticamente as mesmas profissões, tipos de emprego e que não seria possível, portanto, atribuir a essas diferenças o estigma de um grupo a outro.

Assim, em Wiston Parva (nome fictício do lugar), os moradores mais antigos agiam com relação aos recémchegados como se fossem os "herdeiros urbanos, na classe média ou no proletariado, de papéis que haviam desempenhado antes num contexto pré-industrial os senhores, a pequena nobreza rural e a aristocracia" (ELIAS e SCOTSON, 2000, p.105). Os pesquisadores quiseram saber, então, como os membros de um grupo mantinham entre si a crença de que eram seres humanos melhores do que outros e descobriram que esse tipo de configuração é percebido com grande nitidez no contexto de diferenças grupais étnicas e nacionais. Nações poderosas, por exemplo, dominadas por establishments de partidosgovernos, podem produzir, contra os forasteiros, "uma crença social coletiva em sua virtude e graça nacionais ímpares" (ELIAS e SCOTSON, 2000, p. 41).

À semelhança da construção de uma identidade nacional, a pesquisa realizada em Curitiba mostrou-se fértil não só no sentido de se pensar em aspectos de uma identidade curitibana, como também na possibilidade de que essa identidade pudesse conter traços de relações entre estabelecidos-outsiders. Isso ajudou a explicar, em grande parte, os dados encontrados, pois a tensão constante na construção dessa identidade demonstra que esta não estava dada, nem era homogênea como se fazia crer, mas estava em constante disputa. Enquanto grupos de poder mantinham o projeto da cidade ativo, construindo "a Curitiba", "o curitibano" e "o pequeno urbanista", contraditoriamente, faziam emergir, tornavam evidente - às vezes até mesmo sem uma intencionalidade direta - tudo e todos que não faziam parte do projeto. realçando classificações produtoras de importantes diferenças étnico-raciais e de classe. Tais evidências tornavam-se uma espécie de "massa" sobre a qual os outsiders trabalhariam de forma crítica.

Assim, no caso de Curitiba, os dados da pesquisa demonstraram que a tensão nas redes sociais entre grupos mais próximos de práticas estabelecidas e grupos mais próximos de práticas outsiders parece vir de longe. E, enquanto na pesquisa realizada por Elias e Scotson, o tabu produzido pelos estabelecidos se fazia excluindo os outsiders de seus contatos e mantendo tal controle por 
meio de fofocas depreciativas, no caso de Curitiba, o tabu foi se formando de diferentes formas.

Uma eficientíssima constante estrutural percebida foi a de que as vozes estabelecidas da cidade "inventavam tradições", no sentido proposto por Hobsbawm e Ranger (1997), e elegiam e enquadravam determinadas memórias (POLLAK, 1989). Era comum, por exemplo, para os grupos estabelecidos, construírem a história de que o Paraná e sua capital teriam um número menor de negros. Isso seria útil para aproximarem-se, no discurso, de uma ideia europeia e branca de civilização. Ilustra esse aspecto, o trecho de um material de divulgação da cidade, escrito por engenheiros e urbanistas do Instituto de Pesquisa e Planejamento Urbano de Curitiba (IPPUC), que sublinha alguns povos que colonizaram o estado, mas invisibiliza, por exemplo, a população negra:

Feita inicialmente por espanhóis, portugueses, índios e mestiços, a colonização do estado contou ainda com a influência de alemães, poloneses, italianos, ucranianos, entre outros, que vieram a se juntar aos pioneiros para contribuir com o desenvolvimento do Paraná (IPPUC, 2003, p. 23).

Muitos materiais de divulgação valiam-se ainda de fontes de historiadores que, imbuídos do objetivo de contar a história do Paraná e de Curitiba, exploravam, a partir de dados estatísticos, a ideia de que o Paraná tinha menos negros e que seria, como dizia Wachowicz (1995) "um Brasil mais europeu" (ver crítica sobre isso em Moraes e Souza, 1999). Deixavam de destacar o sistema escravocrata como um todo, em Curitiba igual a qualquer outro lugar, como explicitou Ianni (1988) já em 1962.

Os materiais curriculares entregues às escolas da rede municipal, naquele período, também procuravam reforçar essa história branca, utilizando as mesmas fontes históricas "estabelecidas". Uma estratégia encontrada, por exemplo, na Coleção Didática Lições curitibanas (coleção entregue a cada criança da rede municipal na segunda metade da década de 1990 e bastante utilizada ainda na primeira metade da década seguinte), era mencionar questões raciais, na maioria das vezes, de forma generalizada. No trecho abaixo, nota-se que, no diálogo de uma professora discutindo preconceito racial com seus alunos, a situação parece ser comum ao Brasil e não a Curitiba:

- [...] As pessoas negras que vivem hoje no Brasil são descendentes de africanos que possuem, assim como outros povos, tradições, costumes, enfim, toda uma cultura.

- E por que desprezam a gente?

- Bem! Os primeiros negros trazidos ao Brasil foram escravizados, sendo totalmente desvalorizados em sua cultura e em sua humanidade (LIÇÕES CURITIBANAS, 1994, p. 204-209).
Esse desconforto com relação às questões raciais e a invisibilidade dada ao negro na conformação da cidade não apareciam somente nos discursos, livros e materiais escolares e de divulgação da cidade, mas, também, nos próprios mobiliários urbanos da cidade. $\mathrm{Na}$ década de 1990, foram construídos diversos portais étnicos na entrada de diferentes bairros, em homenagem aos imigrantes que "fizeram" Curitiba, sendo que já se denunciava, no final dessa mesma década (MORAIS e SOUZA, em 1999), a inexistência de portais em homenagem ao negro e ao índio.

Outra estratégia utilizada pelos grupos estabelecidos foi romantizar alguns atores da cidade ao longo do tempo. O índio, por exemplo, teve sua imagem harmonicamente apresentada ao lado do homem branco e da igreja e, embora tais relações (índio-igreja-branco) tenham se iniciado e se dado mais frequentemente por volta do século XVII, a construção imagética dessa relação harmoniosa é insistentemente perpetuada ainda no final do século XX. A título de exemplo, é possível mencionar a pintura de Theodoro De Bona representando a lenda que deu origem à cidade e que constava, não só na coleção Lições curitibanas, mas, também, em diversos outros materiais e locais de circulação da cidade. Na pintura, o Cacique Tindiquera aparece "escolhendo" o local para a construção do povoado, mas orientado pela imagem da Nossa Senhora da Luz dos Pinhais, que aparece ao centro do quadro (ver sobre esta questão FERREIRA, 2008).

Ainda com relação a outras interpretações possíveis sobre o índio no estado do Paraná, encontrou-se um livro que aparece como fonte utilizada em diversos outros materiais de divulgação da cidade na década de 1990 (seu autor, WACHOWICZ, escreve sobre essa questão na década de 1970, mas teve seus livros reeditados nas décadas seguintes e, inclusive, no início do século XXI) e que descrevia a relação do índio com a igreja. Por exemplo, de forma pouco crítica. Pode-se lembrar de uma descrição dos "intrépidos missionários" jesuítas como tendo conseguido "fazer penetrar no ânimo dos indígenas os sentimentos de trabalho sistemático e disciplinado, o que até então ninguém havia realizado" (WACHOWICZ, 1995, p. 28). Ainda com relação ao índio, vale mencionar o fato de que alguns parques da cidade, embora tenham nomes indígenas, preservam, na verdade, tradições de imigrantes europeus. É o caso, por exemplo, do Parque Tingui, que tem uma estátua do índio Tindiquera na sua entrada, mas perpetua, na verdade, a memória (com direito à igreja, a objetos e a monumentos) da cultura ucraniana.

Outra estratégia utilizada pelos establishments foi a de pasteurizar as histórias de alguns atores e grupos sociais ao longo do tempo. Interessando-se por ressaltar uma cidade branca, europeia e, portanto, "culta e civilizada", grupos estabelecidos da cidade enfatizaram sobremaneira 
a história dos imigrantes que aqui chegaram. Estes passaram a compor uma história que desconsiderou as tensões entre etnias, os conflitos entre diferentes gerações de imigrantes que aqui chegaram, as diferentes relações econômico-sociais que mantinham entre si e entre os diferentes grupos étnicos, os anseios e sonhos dos que ficaram em suas terras natais e dos que resolveram imigrar (NADALIN, 1981). Enfim, as particularidades e os problemas envolvidos no processo de imigração. Sobre isso, basta lembrar da situação do polonês, na relação com outras etnias, muitas vezes considerado, na cidade, como o "negro do avesso", ou da situação dos alemães que tinham que responder aqui pelos atos de guerra ocorridos na Alemanha. Dessa forma, livros didáticos, de formação de professores e materiais de divulgação da cidade reforçaram uma história de harmonia interétnica, incluindo, sempre que possível, a clássica imagem de imigrantes de diversas nacionalidades, com seus trajes típicos, de mãos dadas e felizes.

Além da invisibilidade, romantização e pasteurização, outro mecanismo evidenciado nas últimas décadas do século XX foi a própria exclusão geográfica de alguns grupos. Pobres e muitos migrantes nacionais das camadas populares foram sendo excluídos da cidade (inchando cada vez mais a região metropolitana) ou colocados nas suas bordas, muitos na região sul (MOURA, 2001; SOUZA, 2001; SOUZA, 2002; FERREIRA, 2008).

Assim, quem não se parecia com o curitibano idealizado pelo projeto, além de ter sido suprimido das imagens e representações, também foi excluído fisicamente das regiões verdadeiramente reconhecidas como "a Curitiba" (ver sobre isso, por exemplo, em SOUZA, 2001, sobre a região do Boqueirão). Ainda nesse sentido, uma grande estratégia foi criar, ao longo do tempo, um novo mapa mundi no imaginário dos moradores, ou seja, um mapa constituído a partir de seus sentimentos de pertencimento. Neste, Curitiba estaria mais próxima da Europa e dos Estados Unidos (quando não, dentro) e longe do Brasil. Foram encontradas inúmeras manchetes em jornais e outros materiais de divulgação que procuravam construir tal aproximação, como, por exemplo: "Revista americana reconhece o sucesso da cidade..."; "Lerner é aplaudido na chegada de Paris"; "Autoridades novaiorquinas visitam Curitiba" (apud FERREIRA, 2008, p. 140). Outras reportagens procuravam destacar o distanciando entre Curitiba e Brasil: "Se as outras capitais fizessem como Curitiba (...)" (idem, ibidem); "Num país formado por uma colcha de retalhos mal costurada de problemas sociais, a cidade de Curitiba (...) é o maior exemplo de que quando o poder público se faz presente, as coisas podem dar certo, mesmo num país pobre" (FIGUEIREDO e LAMOUNIER, 1996, p. 25); ou ainda, "Vamos saber por que Curitiba é o Brasil que pode dar certo" (TANIGUCHI apud IPPUC, 1992, p. vii).

Ao aproximar ou distanciar a cidade, no discurso, de outros lugares, ao colocar a cidade como "igual a", "diferente de", grupos estabelecidos criavam suas próprias formas de classificação. E, uma vez que as classificações humanas são sempre sociais (MAUSS e DURKHEIM apud MAUSS, 2005) e, portanto, não biológicas ou neutras, a interpretação do seu conteúdo político é essencial para a compreensão das formas de operação desses grupos estabelecidos. Assim, comparar-se à Europa e aos Estados Unidos acrescentaria à identidade do curitibano, ideias de "culto", "inteligente", "civilizado". Nesse sentido, tudo o que pudesse lembrar tais lugares era ressaltado, desde as roupas das crianças que ilustravam o livro didático (estas apareciam com trajes típicos alemães, ucranianos ou poloneses) até as reportagens de jornal. Sendo que, nestas, ainda, até o "frio" era capitalizado: "Aqui perdura a mania da elegância. Acho que pelo frio, a gente de Curitiba sempre está bem vestida para ir ao cinema, ao teatro, ao balé" (GAZETA DO POVO, 1999, apud ALMEIDA, 2006, p.78).

Houve também outras estratégias de manter o poder por parte dos grupos estabelecidos, como institucionalizar artistas e intelectuais que propunham leituras diferentes sobre a cidade: criou-se a "Ópera Paulo Leminski" em homenagem ao poeta curitibano que fazia uma séria crítica à cidade; Potty Lazzarotto, pintor famoso no Brasil e no exterior, que ilustrou a revista Joaquim (revista que fazia seria crítica ao Paranismo), tornou-se uma espécie de "pintor do rei", uma vez que começou a ilustrar em murais, ícones e símbolos criados pelos prefeitos da cidade, principalmente os da década de 1990 (como o ligeirinho, a ópera de arame etc).

Intelectuais que propunham diferentes interpretações da cidade, como o já mencionado poeta Paulo Leminski ou ainda o contista Dalton Trevisan, dois expoentes do campo literário curitibano e nacional, por exemplo, quase nunca ou ocasionalmente se mencionavam. Numa das lições da coleção didática Lições curitibanas, após uma citação breve desses autores, dava-se grande destaque a literatos ligados ao movimento paranista. Enfatizavase tanto o amor incondicional ao Paraná quanto se fazia uma ode aos símbolos paranistas como a gralha, o pinhão e o pinheiro (LIÇÕES CURITIBANAS, 1995, p. 525). Essa diversidade de símbolos paranistas aparece também diretamente capitalizada pelo campo curricular. No jornal Curitibinha (publicação entregue a cada criança da rede municipal entre os anos de 1995 e 2000), enquanto a criança coloria e procurava os "7 erros" em uma figura, aprendia também sobre determinados aspectos da cidade e seus símbolos, e isso tudo por meio de personagens como: Curitibinha (o principal, de cabelos verdes, uma alusão 
à capital ecológica); Sorriso (uma árvore Araucária, símbolo do Paraná); Graciosa (menina loira, de olhos azuis, que sempre vestia roupas de cor rosa); Celeste (a gralha azul); Tio Barigui (de descendência italiana) entre outros tantos.

Dentre as constantes estruturais de uma relação como a do tipo estabelecidos-outsiders, Elias e Scotson ressaltaram ainda que, no caso de Winston Parva, a coesão entre os grupos estabelecidos se dava pela união entre as famílias antigas na região que, por se conhecerem por muito tempo, tinham objetivos, condutas, ideias em comum. Em contraste, os recém-chegados eram estranhos não apenas para os antigos moradores, mas também entre si, o que dificultava que criassem coesão.

A construção de uma ideia de "nós" e de "eles" também se verificou no caso curitibano. Na época da pesquisa, os moradores nascidos em Curitiba representavam apenas $50 \%$, os outros $50 \%$ eram compostos por pessoas vindas de outras cidades do Paraná e do Brasil. Assim, muitos dos curitibanos nascidos ou moradores há tempos, na cidade (grande parte descendente de imigrantes europeus), reforçavam laços entre si a partir da imagem de suas origens europeias, em consonância, inclusive, com o projeto da cidade. Uma moradora antiga explicita esse sentimento de "nós", também apontado diversas vezes por Elias: "Acho que talvez seja o grande mérito de Curitiba, essa condição de vida, o estilo de vida. O tipo de população também. É um cadinho de origens europeias" (apud SANTOS, 1995, p. 40). Outra moradora escreveu ainda sobre o momento em que a cidade começou a se industrializar, crescer, ficar mais urbana (por volta da década de 1960): "Curitiba, hoje, tornou-se, inclusive, uma cidade agressiva e perigosa, exatamente em função dessa corrente migratória" (apud SANTOS, 1995, p. 39). Outra moradora, ao falar sobre esses novos moradores, deixa explícito o sentimento sobre "eles": "Não vamos fazer a discriminação da coisa, mas veio gente que não agrada" (p.39). Segundo alguns depoimentos, esses novos integrantes teriam tornado a cidade mais suja, agressiva e desorganizada.

Haveria, portanto, uma tendência de fortalecimento do projeto por parte dos moradores mais antigos e de questionamento por parte dos que chegavam. Esses últimos, estranhando os hábitos da cidade, sentindo-se excluídos do projeto, teriam maiores possibilidades de questionar as imagens e práticas propagadas, como fez, por exemplo, Fernando Pessoa, que, morando já alguns anos na cidade, escreveu a crônica "Curitiba, a fria: onde Jânio Quadros comia moscas". Embora Pessoa tenha escrito a crônica em 1966, esta foi reeditada no início dos anos 2000 (apud IDÉIAS, 2005). Se na época causou comoção geral e pedido de retratação dele pelos políticos da cidade, no século XXI, indícios mostram que alguns curitibanos continuam não aceitando críticas sobre seu comportamento. Ver, por exemplo, o caso de uma artista que, em 2007, ao argumentar que o tipo de colonização do Paraná produziu paranaenses reprimidos, conduziu a um mesmo pedido de retratação "aos imigrantes ofendidos" por políticos da Assembleia Legislativa (apud FERREIRA, 2008, p. 79). Mas dizer que somente realiza outra leitura da cidade quem vem de fora não é verdade. Dados empíricos coletados demonstraram que muitos curitibanos nascidos aqui ou moradores há muito tempo, na cidade, advindos de distintos campos, também realizam ampla crítica à urbe. Leminski e Trevisan, entre outros, do campo literário - como ainda se verá na sequência -, seriam bons exemplos, mas, também, uma série de intelectuais e pesquisadores curitibanos, nascidos na cidade.

Já para divulgar a porção pior da cidade, geralmente, depreciavam-se os bairros da periferia. Sobre o bairro Tatuquara, por exemplo, jornais insistentemente o definiam como violento. Sobre essa operação, um trecho escrito por um rapper morador do bairro denunciava: "Em versos Tribuna [do Paraná], jornal ou hipocrisia/ pega o podre de semana e esconde o que é bonito/de cada dia" (apud SOUZA, 2002, p. 110).

Uma grande chave explicativa sobre o acúmulo de poder dos grupos estabelecidos, tratado por Elias em muitas das suas obras, é que este advém do grande nível de coesão conquistado. No caso de Curitiba, isso também ficou evidente, sendo que a coesão se dava pela quantidade e complexidade de alianças, vantagens, enaltecimentos fortalecedores do próprio grupo e do projeto da cidade. Um exemplo desse tipo de aliança pode ser constatado a partir do depoimento destacado por Oliveira (2000, p. 100), em que um entrevistado, contando sobre a época em que Jaime Lerner assumiu a prefeitura da cidade pela primeira vez (depois de deixar a presidência do IPPUC, em 1971), diz: "Usando da posição obtida, ele [Lerner] imediatamente nomeou para todas as funções relevantes na administração os seus companheiros de IPPUC". Outro indício de coesão também foi relatado por Soares de Oliveira (2005), que demonstrou como grupos literários favoráveis ao Paranismo (dessa vez, buscando um exemplo de início do século XX) procuravam editar somente autores paranistas. Outro exemplo ainda, bem mais próximo do recorte temporal da pesquisa, é o de uma empresa de cerveja que, na década de 1990, considerando-se apta a contar "a" história de Curitiba (Urbana), enaltecia sobremaneira o campo da política e do urbanismo. Assim, por meio da distribuição de suportes para copos de cerveja pelos bares da cidade, selecionava-se e disseminava-se uma determinada história.

Outro material ilustra também a relação do campo econômico com o projeto de cidade. Trata-se de folhas de proteção colocadas nas bandejas de lanches de uma 
grande empresa de fast food internacional, no mês de aniversário da cidade, anos atrás. Essas folhas ressaltavam diversos mobiliários urbanos que contavam uma história branca e ecológica. Além da ilustração de determinados parques (a maioria encontrados na região central e no norte da cidade) e símbolos (alguns religiosos), acima do texto "Amo muito Curitiba", apresentava-se a imagem de um determinado tipo de cidadão: uma curitibana que caminhava pela cidade com o seu cachorrinho.

Outra característica de uma relação do tipo estabelecidos-outsiders diz respeito ao grupo que se inclina a atribuir ao conjunto de outsiders as características "ruins" de sua porção "pior", enquanto "a autoimagem do grupo estabelecido tende a se modelar em seu setor exemplar, ou seja, "na minoria de seus 'melhores' membros". (ELIAS e SCOTSON, 2000, p. 23). Em Curitiba, alguns exemplos mostraram exatamente essa operação. Um exemplo pode ser demonstrado pelo enaltecimento do prefeito Jaime Lerner, o que demonstra que se atribuía o "sucesso" da cidade a apenas uma pessoa ou a alguns poucos campos (da arquitetura e do urbanismo, por exemplo). Assim, manchetes anunciavam: "Um salto do $3^{\mathrm{o}}$ para o $1^{\mathrm{O}}$ mundo. A transformação de Curitiba, Cidade Ecológica, do prefeito Jaime Lerner", ou ainda, "União internacional dos arquitetos reconhece trabalho dele [Lerner] como exprefeito de Curitiba" (apud FERREIRA, 2008, p. 140). Os materiais curriculares da época também fizeram a sua parte. Reportagens no jornal infantil Curitibinha, por exemplo, apresentavam entrevistas com prefeitos para contar sobre o sucesso da cidade.

Percebe-se nesse sentido uma estratégia importante de ensinar aos pequenos curitibanos, desde cedo, que um agrupamento social, no caso a cidade, pode ser pensado por indivíduos particulares, por algumas poucas instituições e campos. Sobre isso é importante lembrar que cada indivíduo, mesmo o mais poderoso, mesmo o chefe tribal, o monarca absolutista ou o ditador, fazem parte do arcabouço básico de funções interdependentes desta sociedade (ELIAS, 1994a). Tais pessoas são representantes de uma função que só é formada e mantida em relação a outras funções, as quais só podem ser entendidas em termos da estrutura e das tensões específicas desse contexto total. Daí tornar-se impossível explicar a cidade segundo apenas as ações de seus prefeitos ou pelo campo da arquitetura e urbanismo, por exemplo.

Outro padrão estrutural percebido na cidade foi o de grupos estabelecidos fazerem sempre referência a indivíduos quase mágicos que produziam o "sucesso" da cidade. "Tudo o que Lerner toca vira ouro", ou ainda, "tudo o que o Jaime toca não vira ouro, vira qualidade de vida" (apud SÁNCHEZ, 2001, p. 158). Além disso, procurava-se reforçar também a ideia de que estes só precisariam deter a técnica urbana. Assim passava-se a mensagem de que o sucesso de Curitiba se devia ao fato de que a prefeitura esteve, na década de 1990 (e em alguns momentos das décadas anteriores também), quase sempre nas mãos de bons técnicos (urbanistas, arquitetos e engenheiros). E pouco importavam suas atuações e defesas no campo político. Um livro sobre cidades brasileiras bemsucedidas, escrito por economistas, contava "a" história da cidade: "Um engenheiro e arquiteto sem muito jeito para a política assumiu pela primeira vez o cargo de prefeito" (FIGUEIREDO e LAMOUNIER, 1996, p. 28). Tal estratégia acabava contribuindo para despolitizar os cidadãos, pois criava a sensação de que eles estariam pouco instrumentalizados para pensar e interferir nos rumos políticos da cidade, uma vez que não detinham a "técnica" urbana. Ainda a esse respeito, o diretor do IPPUC, em 1990, e posterior prefeito da cidade por dois mandatos consecutivos (entre 1997-2000 e 2001-2004), explicando sobre a construção do projeto da cidade, disse: "É claro que a comunidade tem que ser ouvida, mas há que se respeitar a bagagem do técnico" (TANIGUCHI apud IPPUC, 1990, p. 57).

$\mathrm{O}$ argumento ad nauseam de que todo curitibano deveria ser um urbanista, aparecia em diferentes meios e instituições. Uma revista on-line do IPPUC (IPPUC, 2003), por exemplo, com o objetivo de passar a mensagem de que as crianças curitibanas eram, desde pequenas, verdadeiras urbanistas, mostrava desenhos de crianças em que estas reproduziam soluções já criadas para a cidade e não, de fato, soluções pensadas pelas próprias crianças. Em outras palavras, nem as crianças foram instigadas a pensar sobre a cidade e nem se realizou uma verdadeira "escuta" do que pensava a infância curitibana. Já na coleção Lições curitibanas a ideia do curitibano-urbanista se restringia à de que todo cidadão deveria aceitar a direção dada pelos técnicos-urbanistas. Um trecho da coleção ensina sobre isso:

O cidadão curitibano deve sentir-se parte da cidade. Deve ter a consciência de reconhecer e de respeitar a obra daqueles que a construíram e de, ao mesmo tempo, sentir-se responsável por ela (LIÇÕES CURITIBANAS, 1994, p. 134).

Outra estratégia dos grupos estabelecidos foi o destaque dado à moral e aos valores curitibanos (ligados muitas vezes aos valores cristãos). $\mathrm{Na}$ abertura de todos os livros da coleção Lições curitibanas, o prefeito que sucedeu Lerner, Rafael Greca, escrevia:

Os ensinamentos de vida, o saber acumulado pela humanidade, na sua trajetória desde o Jardim do Paraíso até a modernidade, tornam-se familiares aos alunos, pelo emprego de "categorias curitibanas". Aqui se ensina a ler, a escrever e a contar, com a paisagem, a memória e os personagens de Curitiba. Trata-se de um Manual de Cidadania. 
E esperava-se que a coleção fosse recebida pelos alunos com "o carinho que merecem todas as criações destinadas a difundir o Bem e a Verdade".

\section{REDES OUTSIDERS: ESTRATÉGIAS DE POUCA COESÃO NA TESSITURA DO PROJETO DA CIDADE}

Se, por um lado, diversos grupos estabelecidos obtinham poder pela coesão em torno do projeto da cidade, por outro, os grupos outsiders questionavam justamente essa forma de manutenção do poder. Mas, enquanto práticas, imagens e discursos estabelecidos circulavam rapidamente por redes de interdependência importantes da cidade, quais as atuações dos grupos outsiders? Que leituras de cidade faziam? Como operavam de sorte a fazer circular suas imagens, ideias e práticas? O currículo oficial da rede oferecia possibilidades para outras leituras possíveis de cidade?

A pesquisa demonstrou que, muitas vezes, quando se encontrou um argumento com amplo poder simbólico, produtor de forte coesão por parte dos grupos estabelecidos, vozes outsiders, às vezes do mesmo campo, às vezes de campos diferentes e em momentos distintos, rebatiam o discurso. E, embora, na maioria das vezes, tais vozes, de antemão, já se considerassem dissonantes, ocorreram alguns casos em que não se pôde saber ao certo como as próprias vozes se consideravam na relação com o discurso estabelecido, ainda que suas produções pudessem ser interpretadas como outsiders.

Assim, ao mesmo tempo em que uma história escrita na forma de poesia procurava contar às crianças sobre o início da colonização da cidade de forma romantizada, foram encontrados alguns poucos materiais que procuravam desconstruir tal discurso. Abaixo, primeiro a poesia:

\author{
No planalto verdejante, \\ Tímida vilinha \\ Aos poucos desabrochou, \\ Resplandecendo à luz do ouro, \\ Cidade Sorriso se tornou \\ Ivany \\ (LIÇÕES CURITIBANAS, 1994, p. 227).
}

Ainda que não fossem versões propriamente escolares ou históricas e nem de produções de ampla circulação, foram encontradas algumas versões outsiders sobre isso. Uma delas, em um livro sobre a arquitetura de Curitiba, mostra, de forma bem-humorada, que de início a cidade era bem pobre e pouco conhecida: "Havia uma piada, divulgada pelo jornal $O$ Pasquim, que dizia que ritiba, em tupi, significava "do mundo", donde o nome da cidade ser Curitiba" (DUDEQUE, 2001).
E, na medida em que o tradicional historiador do Paraná, visto anteriormente, descrevia os jesuítas como "intrépidos missionários", o poeta Leminski dizia, na década de 1980, no livro Anseios crípticos:

Para transformar um bugre bravio em índio 'missioneiro', o jesuíta tinha que, primeiro, extrair-lhe a alma. Quer dizer, demolir sua cultura. A fé em suas crenças. Seus ritos. Suas danças sexuais. Seus cantos mágicos. O prestígio dos seus pajés. [...] num exercício de violência cultural de fazer inveja aos mais zelosos braços direitos de Hitler (LEMINSKI, 1986, p. 24).

Enquanto discursos estabelecidos procuravam produzir na memória dos curitibanos a ideia de que Curitiba começou a se desenvolver a partir da "Era Lerner", na década de 1970, e com mais força ainda na década de 1990 (também pelos esforços do prefeito e depois governador Jaime Lerner), pesquisadores apontavam outras explicações. Vale verificar primeiro um trecho dessa "história estabelecida" contada por economistas:

\footnotetext{
Na mesma época em que o crescimento de Curitiba começou a se acelerar, no princípio dos anos 70 , um engenheiro e arquiteto [...] assumiu pela primeira vez o cargo de prefeito municipal [...] Tratava-se de Jaime Lerner, um nome que passaria a se confundir com a própria história da tricentenária Curitiba nos 25 anos que se sucederam. [...]. Lerner [...] fez intervenções no ritmo de crescimento da cidade [...] mas, para chegar a esse estágio, os administradores de Curitiba gastaram horas em suas pranchetas, desenhando um modelo de cidade ideal (FIGUEIREDO e LAMOUNIER, 1996, p. 28).
}

Já um historiador a partir de entrevistas com moradores antigos na cidade - estes com idades entre 50 e 80 anos e com atuação ativa em diferentes campos (alguns até mesmo no campo do urbanismo) - revelou que, na memória destes, a cidade já vinha se alterando, modernizando-se desde a década de 1950. Os entrevistados constatam que isso aconteceu por causa das Comemorações do Centenário da Emancipação do Paraná (1953), ou mesmo, como outros prefeitos e governadores, como se vê em entrevista colhida por Santos (1995, p. 91):

(...) como a obra do Centenário, foi feito a maioria das coisas que tem em Curitiba; pelo menos iniciado como obras para essa comemoração, em 1953. Teatro Guairá, Biblioteca Pública, Centro Cívico em construção até hoje -, o Grupo Tiradentes (...). Então, a Curitiba de 53, quer dizer, a partir de 53 que começou, assim, o desenvolvimento de Curitiba.

Ainda sobre esse aspecto de crescimento e desenvolvimento da cidade, historiadores (alguns desde a 
década de 1970 e outros nas décadas seguintes) procuraram discutir os motivos pelos quais a cidade recebeu, na década de 1960, nova leva de migrantes do interior do estado e de regiões próximas. Quer seja pelas explicações sobre as geadas ocorridas no início da década (e pelas perdas das safras e consequente mobilização de pessoas no estado e fora dele), quer seja pela supersafra nacional de café do período (o que ocasionou a contenção de novas plantações) ou pelas tensões entre prosseguir sua vocação agrária ou pender para a industrial $^{4}$, o fato é que tais historiadores põem acento em uma complexa rede de situações. E estas impulsionaram a cidade a alterar sua configuração (tornando-a mais urbanizada e industrializada) e não se aproximam de argumentos centrados apenas na figura de Jaime Lerner. Assim, diversas foram as questões que teriam contribuído para que a década de 1960 (e um pouco antes e também um pouco depois dele) tivesse sido decisiva para que a cidade começasse a planejar ${ }^{5}$, modificar-se e crescer.

Na medida em que as vozes estabelecidas divulgavam a ideia de que só os técnicos estariam capacitados para administrar Curitiba, vozes dissonantes procuravam desmontar esse discurso ao longo das últimas décadas. Moura e Kornin (2001), pesquisadoras do Instituto Paranaense de Desenvolvimento Econômico e Social (IPARDES), por exemplo, analisaram o debate eleitoral e os programas veiculados pelos partidos na televisão, no horário gratuito, em 2000, no primeiro turno das eleições para prefeito. Elas denunciaram o quanto o candidato da posição (o então prefeito Cássio Taniguchi, que tentava a reeleição) ressaltou a imagem de técnico e urbanista competente, aparecendo sentado entre pranchetas e material de arquitetura. Além disso, sofrendo a crítica pela falta de participação popular e correndo o risco de perder as eleições, o prefeito lançou mão diretamente de Lerner, que invadiu a casa dos curitibanos, assumindo a paternidade do projeto da cidade e colocando seu candidato como participante desse processo de criação. Dizia Lerner: "Boa noite, Curitiba (...). Falo menos como governador e mais como curitibano que, com a confiança de todos vocês, teve a honra de ser prefeito da

\footnotetext{
4 Sobre a tendência do estado em diminuir sua ênfase agrária e investir na industrialização do Paraná, também foram encontradas diferentes indicações no tempo histórico e diferentes argumentos conforme grupos e campos. Ver por exemplo diferenças entre explicações de Wachowicz (1995), Figueiredo e Lamounier (1996) e Oliveira (2000). Um balanço sobre essas diferentes explicações encontra-se em Ferreira (2008).

5 É nessa década que surge o IPPUC (Instituto de Pesquisa e Planejamento Urbano de Curitiba) e nascem planos importantes de alteração da cidade, como o Plano Preliminar de Urbanismo (ver em SOUZA, 2001) e originado deste, o Plano Diretor da Cidade (ver OLIVEIRA, 2000). E, embora Lerner tenha participado ativamente do IPPUC nesse período, há que se lembrar que diversas pessoas e uma rede tensa de interesses entre campos existiam (ver OLIV EIRA, 2000).
}

cidade por três vezes (...)" (apud MOURA e KORNIN, 2001, p. 10).

E, de todos os campos em que foi possível analisar textos, imagens, discursos, mobiliários urbanos etc, o literário apresentou-se como um dos mais férteis para provocar novas leituras da cidade, diferentes das oficiais (ver sobre isso, FERREIRA, 2008). Tal campo foi extremamente hábil em escrever e fazer circular questionamentos sobre as explicações únicas a respeito do "curitibano", dos discursos sobre a capital ecológica; enfim, das "verdades" da urbe. Trevisan, por exemplo, um crítico da cidade por mais de 50 anos, escrevia no livro Em busca da Curitiba perdida:
[...] a melhor de todas as cidades possíveis nenhum motorista pô respeita o sinal vermelho Curitiba europeia do primeiro mundo
cinqüenta buracos por pessoa em toda a calçada
Curitiba alegre do povo feliz
essa é a cidade irreal da propaganda ninguém não viu não sabe onde fica falso produto de marketing político ópera bufa de nuvem fraude arame cidade alegríssima de mentirinha povo felicíssimo sem rosto sem direito sem pão dessa Curitiba não me ufano não Curitiba não é uma festa os dias da ira nas ruas vêm aí [...] (TREVISAN, 2003, grifos em itálico do autor).

Literatos mais recentes, que escreviam no final da década de 1990 e início dos anos 2000, utilizavam constantemente tais discursos "únicos" sobre Curitiba, como um "combustível" para a produção de outras possibilidades de leitura da cidade, como, por exemplo, no conto de Roberto Gomes "Aquele primo visita Curitiba", que circulou no jornal Gazeta do Povo:

\footnotetext{
Quando passamos pela Vila Pinto, ele, impaciente, perguntou:

- E quando chegaremos a Curitiba?

- Aqui já é Curitiba, primo [...]

- Mas estas casas de madeira, papelão, pano? Trata-se de algum projeto ecológico?

- Não, primo. É favela mesmo.

- Favela? Em Curitiba?!

O primo abriu uma maleta, dela retirando uma pilha de folders.

- Muito estranho, comentou, remexendo na papelada (apud ALMEIDA, 2006, p. 28).
}

E são incisivos em criticar uma determinada classe média fútil, como, por exemplo, no trecho: "O paranaense típico é um grande comedor de picanha e um péssimo consumidor de livros" (SNEGE apud ALMEIDA, 2006, p. 149), ou ainda: 
A insaciável fome de cultura das elites: Hebe Camargo às segundas, joguinho de tranca na quarta, Faustão e Silvio Santos no domingo, que ninguém é de ferro (...) Os passeios dominicais nos parques da cidade. Madames com celulite desfilando seus cãezinhos (p. 83).

E vale lembrar que, na maioria das vezes, ao criticarem tão abertamente a cidade e o cidadão, tais cronistas provocavam a ira de muitos curitibanos leitores dos jornais nos quais os textos eram veiculados, dando pistas sobre os possíveis efeitos de coesão produzidos pelos grupos estabelecidos. Um leitor, após ter lido uma das crônicas de Snege, rebateu, na seção de cartas:

Espero sinceramente que o colunista, como tantos outros que criticam esta cidade, façam (sic) uso da quarta estação por ele citada, a rodoferroviária, que presta excelentes serviços a quem queira deixar esta Curitiba que tanto os incomoda (apud ALMEIDA, 2006, p. 33).

Outro leitor ainda, sobre a reportagem: "A beleza postiça de Curitiba", rebate como um bom paranista: "Salta aos olhos o posicionamento 'postiçointelectualóide' de quem o assinou! Que a gralha azul ilumine seus pensamentos!" (p. 33).

Já com relação ao material curricular analisado, percebeu-se pouca possibilidade de que textos e imagens outsiders tivessem entrado no currículo oficial da rede. $\mathrm{O}$ que talvez pudesse propiciar uma participação maior das crianças no projeto da cidade e, assim, demonstraria uma visão de infância menos ingênua como a que o material curricular do período anunciava.

Ainda sobre os materiais curriculares, na virada do século, há um gradativo abandono do uso da coleção didática nas escolas, o jornal Curitibinha interrompe sua edição e novas demandas parecem se colocar ao governo Taniguchi (1997-2000/2001-04). E este precisa agora conciliar o projeto centralizador da capital ecológica com as demandas descentralizadoras advindas do governo federal e com a introdução nas escolas, por exemplo, de projetos empresariais (FERREIRA, 2008).

Mas, ao mesmo tempo em que se assiste a outro tipo de administração cada vez mais voltada para a eficácia e descentralização e para a entrada de diversos projetos na escola, rompendo-se, inclusive, com o currículo disciplinar, percebe-se também uma forte continuidade da relação entre a cidade e as escolas. Estas passam a ser convidadas a organizar seus currículos por temas e projetos de trabalho e a partir de problematizações que possam discutir questões como as da comunidade, do meio ambiente, da cidade ${ }^{6}$. As tradicionais áreas do saber devem se envolver nos projetos na medida em que auxiliem a responder às questões propostas, e tudo isso deve ser embasado em Diretrizes Curriculares Municipais que expressam, como princípios básicos, elementos e vocabulário advindos do mundo das ciências naturais ${ }^{7}$, em um processo que de longe separa as escolas da rede municipal e seu currículo de um projeto maior de cidade.

\section{CONSIDERAÇõES FINAIS}

Quando se analisaram os embates entre discursos e ações de grupos estabelecidos e outsiders, verificou-se que, embora existisse uma luta entre essas vozes pela melhor representação da cidade e, ainda, imagens em disputa e classificações contrastantes sobre o curitibano, as vozes estabelecidas operaram de sorte a manter com sucesso um projeto muito específico em andamento.

Para isso, um grupo advindo de um campo estabelecido evocava, mencionava outro grupo de outro campo, ou diversos campos unidos construíam representações, imagens, ações. Enfim, todo um discurso convincente que, repetido incansavelmente, entre diferentes campos, fazia com que as vozes oficiais produzissem certezas e criassem um discurso de autoridade, performativo, de forte poder simbólico (BOURDIEU, 2000). A força dessa rede de interdependência estava justamente aí, na coesão obtida por esses discursos e na desestruturação causada nas redes outsiders.

Por outro lado, observou-se que, mesmo com poder, os discursos estabelecidos não eram aceitos tão facilmente e de forma homogênea por todos os grupos e atores da cidade. Os dados demonstraram um rebater constante de argumentos, muitas vezes, até mais qualificados, por parte de determinados campos e grupos. Mas por que os outsiders não tiveram força para fazer valer suas leituras, imagens e representações de cidade?

Tais discursos concentravam menos poder na disputa, quer seja pelo seu conteúdo (um discurso com menor poder de convencimento do que o propagado pelas vozes estabelecidas, impregnadas de poder simbólico), quer seja pela forma com que procuravam fazê-lo circular, como por meio de livros, teses, dissertações, imagens etc. Tais produções não tinham o poder de divulgação e de circulação que dispunham, por exemplo, os produtores dos discursos oficiais. Estes podiam mobilizar diferentes

\footnotetext{
${ }^{6}$ Exemplos de projetos desenvolvidos: Lixo que não é lixo; Reciclagem e reaproveitamento do lixo; Melhorias no bosque; Curitiba ontem e hoje; Consumo sustentável. Fonte: Arquivo Ativo da SME - Projetos Políticos Pedagógicos das escolas da rede (2001-2003).

7 Um dos três princípios das Diretrizes Curriculares Municipais (19972000) era o da educação para o desenvolvimento sustentável, que deveria ser trabalhado respeitando-se outros cinco princípios: interdependência, reciclagem, parceria, flexibilidade, diversidade.
} 
verbas, formas de publicidade e se inscrever nos espaços da cidade a partir de diferentes mobiliários urbanos, intervenções artísticas e mesmo desenvolvê-los nas escolas e em outras instâncias públicas.

Já muitos discursos outsiders, como, por exemplo, os científicos, pela possibilidade de utilização do método científico na análise das questões sociais, denunciavam justamente o poder simbólico dos grupos estabelecidos, as memórias e as histórias forjadas, inventadas, enquadradas. E determinadas produções artísticas, filosóficas ou literárias com diferentes linguagens (como a poesia, o conto, a música) ofereciam outras possibilidades de interpretação da cidade, como no caso de Trevisan que, ao dar voz a personagens comuns da cidade (suas histórias partiam sempre de personagens como a vendedora, a prostituta, o trabalhador, o bêbado), construía outra imagem, bem menos "exemplar" de Curitiba. Enfim, os discursos outsiders eram dissonantes, silenciados, ou pouco ouvidos, justamente porque davam voz a grupos silenciados, a sujeitos excluídos ou denunciavam as "verdades" produzidas pelos grupos estabelecidos.

Já no campo educacional, a Secretaria Municipal de Educação, ao desenvolver diretrizes e materiais curriculares em consonância com o projeto da cidade e trabalhar na conquista da adesão de crianças e famílias curitibanas a tal projeto, produziu um currículo muito mais estabelecido do que outsiders (nesse último caso, imaginando-se um currículo que possibilitasse diferentes leituras da cidade, da escola, da infância e fosse questionador de verdades instauradas).

A proposta curricular oficial ofereceu às crianças da rede municipal a oportunidade de que compreendessem a cidade de forma conservadora e pouco crítica. O diálogo mantido entre cidade e infância, naquele período, parece ter proporcionado a que as crianças tenham crescido com a oferta de uma interpretação restrita - a dos grupos estabelecidos - para pensar os espaços de socialização da cidade, bem como com uma visão pouco politizada e individualista dos problemas socioambientais.

\section{REFERÊNCIAS}

ACSELRAD, Henri (Org.). A duração das cidades: sustentabilidade e risco nas políticas urbanas. Rio de Janeiro: DP\&A, 2001.

ALMEIDA, Camila Gino. Um cronista na cidade: Curitiba no jornal sob o olhar de Jamil Snege 1997-2003. 2006. 279 f. Dissertação (Mestrado em Letras) - Programa de PósGraduação em Letras do Setor de Ciências Humanas, Letras e Artes, Universidade Federal do Paraná, Curitiba.

BOURDIEU, Pierre. O poder simbólico. 3. ed. Rio de Janeiro: Bertrand, 2000.

DUDEQUE, Irã José Taborda. Espirais de madeira: uma história da arquitetura de Curitiba. São Paulo: Studio Nobel, 2001.
ELIAS, Norbert. A sociedade dos indivíduos. Rio de Janeiro: Zahar, 1994a.

ELIAS, Norbert. O processo civilizador I: uma história dos costumes. Rio de Janeiro: Zahar, 1994b.

FERREIRA, Valéria Milena Rohrich. Tecendo uma cidade modelar: Relações entre currículo, educação escolar e projeto da cidade de Curitiba na década de 1990. Tese (Doutorado em Educação) - Pontifícia Universidade Católica de São Paulo, 2008.

HOBSBAWM, Eric; RANGER, Terence. A invenção das tradições. 4. ed. São Paulo: Paz e Terra, 1997.

IANNI, Otávio. As metamorfoses do escravo. 2. ed. São Paulo: Hucitec, 1988.

LEMINSKI, Paulo. Anseios crípticos: (anseios teóricos). Peripécias de um investigador do sentido no torvelinho das formas e das ideias. Curitiba: Criar, 1986.

MAUSS, Marcel. Ensaios de sociologia. 2. ed. São Paulo: Perspectiva, 2005.

MORAES, Pedro Rodolfo Bodê de; SOUZA, Marcilene Garcia de. Invisibilidade, preconceito e violência racial em Curitiba. Revista de Sociologia Política, Curitiba, n. 13, p. 7-16, nov. 1999.

MOURA, Rosa. Os riscos da cidade modelo. In: ACSELRAD, Henri (Org.). A duração das cidades: sustentabilidade e risco nas políticas urbanas. Rio de Janeiro: DP\&A, 2001.

MOURA, Rosa; KORNIN, Thaís. (Des)construindo o discurso eleitoral: o primeiro turno das eleições municipais majoritárias em Curitiba no ano 2000. Revista de Sociologia e Política, Curitiba, n. 16, p. 67-96, jun. 2001.

NADALIN, Sergio Odilon. Imigrantes alemães e descendentes em Curitiba: caracterização de um grupo social. História Questões \& Debates, Curitiba, v. 2, n. 2, p. 23-35, jun. 1981.

OLIVEIRA, Dennison de. Curitiba e o mito da cidade modelo. Curitiba: Editora da UFPR, 2000.

POLLAK, Michael. Memória, esquecimento, silêncio. Estudos Históricos. Rio de Janeiro, v. 2, n. 3, 1989, p. 3-15.

SÁNCHEZ, Fernanda. A (in)sustentabilidade das cidadesvitrine. In: ACSELRAD, Henri (Org.). A duração das cidades: sustentabilidade e risco nas políticas urbanas. Rio de Janeiro: DP\&A, 2001

SANTOS, Antonio Cesar de Almeida. Memórias e cidade: depoimentos e transformação urbana de Curitiba (1930-1990). 1995. 116 f. Dissertação (Mestrado em História) - Programa de Pós-Graduação em História, UFPR, Curitiba.

SCOTSON, John L. Os estabelecidos e os outsiders: sociologia das relações de poder a partir de uma pequena comunidade. Rio de Janeiro: Zahar, 2000.

SOARES DE OLIVEIRA, Luiz Cláudio. Joaquim contra o paranismo. 2005. 234 f. Dissertação (Mestrado em Estudos Literários) - Programa de Pós-Graduação em Letras, Universidade Federal do Paraná, Curitiba.

SOUZA, Nelson Rosário de. Planejamento urbano de Curitiba: saber técnico, classificação dos citadinos e partilha da cidade. Revista de Sociologia Política, Curitiba, n. 16, p. 1-18, jun. 2001.

SOUZA, Ozanam de. Estigma no bairro do Tatuquara e luta pela conquista da cidadania. 200 f. 2002. Dissertação (Mestrado em Antropologia Social) - Programa de Pós-Graduação em Antropologia Social, Universidade Federal do Paraná, Curitiba. 
TREVISAN, Dalton. Em busca de Curitiba perdida. 8. ed. Rio de Janeiro: Record, 2003.

WACHOWICZ, Rui. História do Paraná. 7. ed. Curitiba: Vicentina, 1995.

\section{Documentos e outros materiais analisados:}

BOLETIM DE INFORMAÇÕES SOCIOECONÔMICAS. Curitiba: Companhia de Desenvolvimento de Curitiba, 2007.

CURITIBINHA: escolar. Curitiba: Prefeitura Municipal de Curitiba, 1995-2000. Jornal mensal.

FENIANOS, Eduardo E. Manual Curitiba: a cidade em suas mãos. Curitiba: UniverCidade, 2003.

FENIANOS, Eduardo; MENDONÇA, Maí Nascimento. Linha pinhão. Curitiba: Prefeitura Municipal, 1996.

FERNANDES, Carlos Renato. Curitiba: Brasil. Curitiba, 2007.

FIGUEIREDO, Rubens; LAMOUNIER, Bolívar. As cidades que dão certo: experiências inovadoras na administração pública brasileira. Brasília: MH Comunicação, 1996.
IDÉIAS: política, economia \& cultura do Paraná. Curitiba: Travessa dos Editores, v. 20, n. 2 (esp.), mar. 2005.

IPPUC - INSTITUTO DE PESQUISA E PLANEJAMENTO URBANO DE CURITIBA. Memória da Curitiba urbana: Escola de Urbanismo Ecológico, Curitiba, maio 1990.

IPPUC - INSTITUTO DE PESQUISA E PLANEJAMENTO URBANO DE CURITIBA. Memória da Curitiba urbana: Escola de Urbanismo Ecológico. Curitiba, jan. 1992.

IPPUC - INSTITUTO DE PESQUISA E PLANEJAMENTO URBANO DE CURITIBA. Revista Espaço Urbano, n. 3, jan. 2003. Disponível em: <http://www.ippuc.org.br/informando/ imagens/Revista03.pdf>. Acesso em: 30 ago. 2012.

LIÇÕES CURITIBANAS. 3ạ série, v. 1 (1994) e 2 (1995). Curitiba: Prefeitura Municipal de Curitiba, Secretaria da Educação, 1994. Coleção Didática.

SAMEK, Jorge. A Curitiba do terceiro milênio. Curitiba: Palavra, 1996.

Submetido em: 17/04/2014

Aprovado em: 18/09/2015 